\title{
Evidence of Climate Change Engagement Behaviour on a Facebook Fan-Based Page
}

\author{
Kirtika Deo ${ }^{1, *(1)}$ and Abhnil Amtesh Prasad ${ }^{2}$ (1) \\ 1 Marketing Discipline Group, UTS Business School, University of Technology Sydney, Sydney, \\ NSW 2007, Australia \\ 2 Climate Change Research Centre, University of New South Wales, Sydney, NSW 2052, Australia; \\ abhnil.prasad@unsw.edu.au \\ * Correspondence: kirtika.deo@uts.edu.au
}

Received: 11 August 2020; Accepted: 26 August 2020; Published: 28 August 2020

\begin{abstract}
Climate change has become one of the most debated topics in recent times. The social media platforms have given the general public the power and propensity to share and express concerns about climate change. However, climate change awareness created on social media depends on user engagement with the contents modulated by emotions. Much has been researched in this area using Twitter, but Facebook fan-based pages have not been extensively explored in the past. In this study, we investigate the engagement behaviour of users on a Facebook fan-based page titled "Global Climate Change Awareness" by analysing user insights data for two years starting from April 2018 to April 2020. Results show that the frequency of posts made to the page did not significantly promote engagement but improved visibility of the contents to the users. Overall, fan growth was attributed more to increased post visibility that enhanced post engagement. Hashtags associated with climate change had a significant reach amongst users, but those associated with disasters where the page expressed sadness and informed users about taking precautions had the highest engagement rate. Likewise, users from developing countries, especially from the small islands, were more engaged with climate change awareness. This study did not assess negative responses from users (possible deniers of climate change) and other Facebook fan-based pages due to data privacy and stringent Facebook policy.
\end{abstract}

Keywords: climate change awareness; social media communication; content engagement; Facebook; engagement behaviour

\section{Introduction}

Nowadays, climate change has become one of the most prevalent topics of discussion and has gained enormous attention in both traditional and social media [1,2]. Television, newspaper and radio outlets have been traditional mediums for discussion about climate change [3]. However, the proliferation of social media has given its users the liberty to create, share, distribute and discuss $[4,5]$ climate change ideologies [6]. Moreover, the diverse ecology of social media provides the public and stakeholders with freedom of expression, control of contents and dialogues $[4,7]$ relating to climate topics.

\subsection{Climate Change}

Climate change has become one of the most significant challenges facing humankind and natural systems [8]. Climate change is defined as the changes in global weather patterns due to an increased level of atmospheric carbon dioxide caused by excessive use of fossil fuels [9]. Titifanue, et al. [10] defined climate change as a human-induced change to the climate system that has been caused by an 
increase in greenhouse gases. Most often, climate change and global warming are used interchangeably to create awareness of the changing climate. Due to climate change and global warming, there is a significant rise in natural disasters such as hurricanes, typhoons, floods, tornadoes and bush fires [11] caused by extreme precipitation and heat. As a result of rising global temperatures, there is strong evidence of the melting of polar ice leading to a rise in sea levels.

Moreover, the increasing heat causes water to expand, which results in thermal expansion of the oceans. As a result of climate change, there is increasing evidence of socio-ecological problems [12]. Natural hazards and disasters have become expensive to cope with, exposing the population to higher risks [13]. Climate change impacts are more pronounced in developing countries due to lack of funds, infrastructure, policies and other economical constraints, which further impedes the potential for development in these countries. To mitigate and adapt to the adverse effects of a changing climate, greater synergy amongst developed and developing nations is vital, and this can be developed through the translation of stringent climate policies to sustainable development strategies [14]. Already, several synergies in climate policies and sustainable development exist in developing countries in various sectors including renewable energy, water security, energy efficiency, sustainable tourism, forests, lands and fisheries $[15,16]$. However, communication about climate change and its impacts amongst the public is the major barrier in developing policies relevant for climate change [17], thus understanding public opinions on issues relating to climate change is essential for sustainable development [18].

Nowadays, social media platforms provide unlimited opportunities to the general public to discuss and share opinions about climate change without any time or geographic restrictions [2]. Moreover, social media has been widely used to prepare and recover from the critical impacts of climate change. Social media provides situational awareness, dissemination of emergency information, delivers early warning systems and helps coordinate relief efforts [11].

\subsection{Climate Change Awareness and Social Media Communication}

Climate change has gained enormous attention from multiple mediums, including traditional and new media [1]. For this study, new media or social media has been taken into consideration because the platform supports and facilitates climate change communication [19]. Social media encourages the free flow of information and knowledge, providing greater awareness about climate change to a general audience. Moreover, the platform provides opportunities to increase information sharing, participation and engagement with climate change contents. Therefore, social media communication encourages environmentally friendly behaviour in its users, leading to mitigation of the adverse effects of climate change and to promoting activism around the issues related to climate change [6].

The emerging trends on climate change communication have seen access to a massive and diverse range of user-generated contents collected from social media to investigate public opinions and the effectiveness of scientific communication of climate change related issues [20]. Moreover, several studies have assessed the sentiments of discussions about climate change or climate change events on various social media platforms [19]. The analysis of user posts, comments and contents provides substantial understanding about public opinions and viewpoints that were inaccessible through traditional media approaches [21]. Facebook and Twitter have been widely used for climate change communication by the general public because both the platforms promote the creation and spread of information, opinions, thoughts and various kinds of expression through virtual communities [8].

Twitter has been a centre for researchers to collect, analyse and report public opinions and viewpoints on climate change [9,21-25]. Moreover, individuals used components of Twitter such as hashtags, retweets and replies that are primarily used to research public opinions and activities on climate change. Andreotta, et al. [21] used a mixed-methods approach to explore Australian-based Twitter posts based on climate change related topics. The study reported positive public perceptions and sentiments about climate change from an Australian discourse. Samantray and Pin [26] used Twitter-based conversations on climate change from the year 2007-2017 and confirmed that the public is likely to be influenced by climate information from reliable and credible sources. Moreover, another 
study used Twitter discussion of climate change during extreme weather events [19]. The study revealed that healthy science-oriented conversations or comments foster healthy public engagement.

Similarly, a study also chose the Twitter platform to analyse public attitudes towards climate change [8]. The study used deep neural networks to differentiate between climate deniers and supporters of climate change on Twitter. In addition, a study investigated the sentiment of tweets that contained the word "climate" and revealed that the public used Twitter as a primary source of information and discussion [27]. The study also reported that climate change and natural disaster news was abundantly available on Twitter for the general public. Recently, Dahal, et al. [22] used geotagged tweets to conduct topic modelling and sentiment analysis, confirming that discussions about climate change were diverse on Twitter. The study mentioned that policy-related topics on climate change were less prominent in the United States when compared with other countries. Similarly, a study used Twitter to capture public awareness on climate change and showed that \#EarthDay promoted significant public awareness participation [23].

Several researchers reported the active use of Twitter in communicating extreme weather events related to climate change. Kryvasheyeu, et al. [11] utilised Twitter activity before, during and after Hurricane Sandy. The study revealed that social networks could be used to assess damages caused by a large-scale disaster. Moreover, social media provides awareness and acts as a useful medium for dissemination of emergency information by enabling early warning signs. Similarly, Twitter data was used to analyse costly disasters in the United States [13] by exploring the public response to disaster types, preparation for the disaster and the recovery information after the disasters. Recently, Twitter posts that used climate change concerning extreme weather events have also been analysed [3]. The study used Hurricane Irene, Hurricane Sandy and Snowstorm Jonas to define high-magnitude extreme weather events and showed that during Hurricane Sandy, the level of climate change discussion was prevalent when compared to during Hurricane Irene or Snowstorm Jonas.

In comparison to Twitter, studies related to Facebook pages and posts communicating climate change are limited. Vraga, et al. [28] demonstrated a strong relationship between the use of Facebook by users to engage with energy-related issues. The study showed that the participants perceived themselves as opinion leaders and had a sense of efficacy for political actions related to climate change. Another study confirmed that Greenpeace used Facebook to effectively disseminate information and contents about climate change campaigns to capture broader public engagement [29]. In Australia, Facebook pages were used during the Queensland and Victoria floods to discuss and provide valuable information about floods, with the virtual communities providing recovery supports and local emergency information [30].

It is evident that Facebook fan-based pages are not substantially researched when compared to Twitter in disseminating climate change-related content [31]. Therefore, this study focuses on investigating user engagement behaviour using a Facebook fan-based page that promotes and educates the global audience about climate change, climate change awareness, mitigation and adaptation related contents, comments, information and infographics.

\subsection{Facebook Fan Pages}

Facebook is currently the largest social networking site (SNS), with 2.4 billion members and more than 1.59 billion daily users [32,33]. Facebook allows the creation of profiles and virtual communities that enhance interactions between the users [34]. The fan pages refer to Facebook profiles that include detailed analytics, better contents and fan administration. Moreover, the fan pages permit the creation of virtual communities around its users or fans [35]. The users or fans are given the freedom to comment, share, express and even disseminate information and contents $[34,35]$ including issues relating to climate, climate change, extreme weather and disasters [2,13]. Social media managers operate the fan pages, and their fundamental tasks are to post and share [36] climate-related contents in the form of graphics, infographics, web links, videos and posts. 
Fan-based pages on climate change connect users who have a similar or common interests, values, goals and visions [33]. Fans take the initiative to "Like" a fan page and receive updated news and updates about climate change related topics. The members or fans perceive the quality level of the contents, which includes the degree of relevance, timeliness and accuracy [33,34,36]. Park, et al. [37] highlighted that fans participate on Facebook groups for entertainment and information seeking based on User and Gratifications theory. There are two types of fans that have been identified in the past [38]. An active fan or member is involved in interactive communication that leads to increased attitudinal commitment, while passive members browse through their feeds and take advantage of the contents and information but do not contribute to the community activities. Lin and Lu [39] identified that members continue to use Facebook fan-based pages for social interactions, shared values and trust. The fan pages provide social communities that evolve into social utility networks that encourage the building of resourceful communities. The contents on fan-based pages are key to stimulate interactions between fans or users [34,36].

On Facebook, the dissemination of contents can be achieved through several mechanisms. The users on the fan page see posts on their feeds and can interact by liking, sharing or commenting. Consequently, fans or users may contribute to exponential dissemination of contents or posts about climate change-related topics [34,40]. Moreover, inclusions of infographics, videos and images lead to significant interaction between the users. The user interaction with the contents posted is crucial to determine the popularity of posts on fan-based pages.

The use of fan-based pages can motivate positive and negative emotions and feelings. The positive feelings increase the chances of developing and maintaining social capital and social connectedness. On the contrary, the fans, at times, may feel exhausted from overloaded information and contents. Nevertheless, Lin and Utz [41] confirmed that positive emotions are prevalent when compared to negative feelings or emotions. Several scholars have also debated whether emotion is a necessary tool for the communication of climate change topics [42]. Huertas and Marine-Roig [43] also showed that communication of emotional brand values generated positive responses from several Facebook fan pages. Overall, emotions are vital for practical and moral decisions that can be applied to communicate climate change. Thus, the emotions of the users or fans are vital for understanding the moral impacts and risks of climate change [42,43].

Therefore, fan-based pages form a vital virtual platform that facilitates engagement behaviour, which social media managers employ to engage with the audiences [44]. Chen and Tsai [45] also demonstrate strong connections between community identification and brand fan-based engagement behaviours. Regardless of the community type, the fans or members participate in several types of behaviours that may range from commenting, sharing information, liking posts, providing feedback or reviews to providing useful information and contents to fellow users and even to social media managers.

\subsection{User Engagement Behaviour}

Public engagement on social media is essential for gaining adequate climate change responses [40]. The extant literature defined engagement from a cognitive, affective and behavioural perspective [46,47]. For this study, the behavioural dimension of engagement is taken into consideration. The concept of "social media engagement behaviour" demonstrates the users' behaviour when they are engaging on social media platforms [46]. In general, the engagement behaviour includes a plethora of activities ranging from electronic word-of-mouth (EWOM) activities, recommendations, sharing, blogging, writing reviews and even participating in legal actions [44,47]. Facebook provides users with an interactive avenue to create value by generating and sharing contents and making contributions through comments and likes [46,47].

In general, the user engagement is aligned with the fan's goals and has three types of positive behavioural manifestations, including consumption, positive contribution and co-creation [47]. On the other hand, the negative valence of engagement activities includes detachment, negative contribution and co-destruction. Similarly, Schivinski and Dabrowski [48] illustrated that engagement levels include 
consumption, contribution and creation. Consumption refers to the passive use of contents without significant contribution and participation. Contribution denotes a medium level of user activity that includes likes, shares and comments, while the creation dimension includes the creation and dissemination of various types of contents.

Overall, user engagement behaviour provides practical benefits, social benefits, social enhancement, entertainment and economic benefits to the audience on Facebook [44]. From a practical benefit perceptive, the fans or members can gain enormous knowledge and understanding about climate change. The social benefits include members participating in peer discussions and giving and receiving help that provides social enhancement, which generates the need to feel useful and helpful. Since audiences are spending an enormous amount of time on Facebook, the entertainment benefits range from relaxation and fun to gaining hedonic value. The economic benefit includes being aware of current and future losses that countries, economies, businesses and individuals may face due to the impacts of climate change [40,44].

Therefore, it is prudent to study the engagement behaviour activities of users interested in climate change related contents on a Facebook fan-based page. Studies in the past have demonstrated a link between social media and climate change awareness were conducted in developed countries such as the USA, UK, Canada and Australia [2]. From the literature, it is evident that there is a substantial level of bias towards Twitter-based research on climate change and social media [31]. The majority of the studies have reported analysing Twitter comments [22], contents, hashtags [23], user attitudes [49] and posts to analyse public viewpoints and understanding about topics related to climate change [9,21-23]. Therefore, there is a lack of studies and contributions to the existing body of literature about the use of Facebook fan-based pages for climate change awareness, education and engagement. Therefore, this paper provides insights about the engagement behaviour [47] and communication activities [2] of climate change by using the data from a Facebook fan-based page. Upon obtaining permission to access fan page data, the data were statistically analysed to measure and report the engagement behavioural activities of the users.

The key research questions for this paper are:

1. What are the emerging trends of climate change awareness on the fan-based page?

2. Which types of climate change-related contents and events are prevalent amongst fans of climate change awareness on Facebook?

3. Are there any emotions connected with the contents posted on the fan-based page and the user engagement behaviour?

It is critical to understand the connections between the fan engagement process and the contents of climate change posted on social media pages [20] such as Facebook for raising awareness. Collectively, climate change awareness using social media may trigger and accelerate greater policy response from stakeholders to mitigate the adverse effects of climate change $[6,28]$. However, enhancing the fan engagement process requires a deeper understanding of the behavioural dynamics of fans $[46,47]$ and the core contents of climate change curating engagement behaviour [31].

After assessing the past literature in Section 1 to identify the research gaps, the paper outlines the materials and methodology used for analysis in Section 2. The results are reported in Section 3, followed by a detailed discussion in Section 4, with the conclusion presented at the end.

\section{Methods and Materials}

\subsection{Facebook Page}

The posts from the Facebook Page titled "Global Climate Change Awareness" (Facebook Page ID: 1061174837230483), for a two-year period starting from April 2018 to April 2020, were used in this study. This page was created on 25 March 2015 by an early career climate scientist aiming to educate the public about the impacts and interventions of climate change around the globe and gained a fanbase of 
around 5000 (total page likes) by the end of April 2020. The number of users who saw posts at least once on this page was dominated by Males (74\%) who were mostly from the age-group of 25-34.

\subsection{Metrics}

In this study, the Facebook Graph Application Programming Interface (API) (version 6.0 was accessed from the Facebook for Developers webpage) and the Facebook Software Development Kit (SDK) for Python (sourced from GitHub) were used to collect user insights from the Facebook page "Global Climate Change Awareness". The key metrics downloaded with a daily frequency are described in Table 1.

Table 1. Summary of Key Facebook Page Metrics.

\begin{tabular}{cl}
\hline Variable & \multicolumn{1}{c}{ Description } \\
\hline Post Frequency & $\begin{array}{l}\text { The number of posts created in a day using the unique post identifiers. } \\
\text { The number of times the page's profile has been viewed by logged-in and } \\
\text { logged-out users. } \\
\text { Page Views }\end{array}$ \\
Page Likes & $\begin{array}{l}\text { The number of new users who liked the page. } \\
\text { Thelude statuses, photos, links, videos and more. } \\
\text { Post Reach }\end{array}$ \\
Post Engagement & $\begin{array}{l}\text { The number of times the users engaged with the page's posts through reactions, } \\
\text { comments, shares and more. }\end{array}$ \\
\hline
\end{tabular}

The Facebook Graph API queries for the metrics above were limited to 90 days [50]. Thus, several API calls were made to accumulate insights from the page, since the downloadable data was only available for the past two years from the date of API access. The Facebook Graph API has been widely used in the past for social research related to user comments on different Facebook pages [51-53].

\subsection{Data Processing}

The key metrics shown in Table 1 were resampled into monthly totals to understand monthly variations. To understand trends in the data, the daily metrics $(m)$ were weighted by daily post frequency $(w)$ to generate a monthly weighted metric $(\bar{M})$ from Equation (1):

$$
\bar{M}=\frac{\sum_{i=1}^{n} m_{i} w_{i}}{\sum_{i=1}^{n} w_{i}}
$$

$\bar{M}$ accounts for irregularities in the number of posts uploaded to the page for trend analysis. The linear trends were calculated using the Python NumPy package with the function polyfit [54].

In addition, further post insights were downloaded using the unique post identifiers to calculate the Lifetime Post Engagement Rate (ER) from Equation (2):

$$
E R(\%)=\frac{\text { Post Engaged Users }}{\text { Unique Post Reach }} \times 100
$$

Higher (or lower) ER indicates posts that were most (or least) engaging amongst fans of the page.

Furthermore, all posts were extracted using the unique post identifiers and analysed further for the most popular hashtags using text analysis from the Python WordCloud package. Note, key words excluded while generating the popular hashtags included "nan", "the", "off", "on", "and", "this",

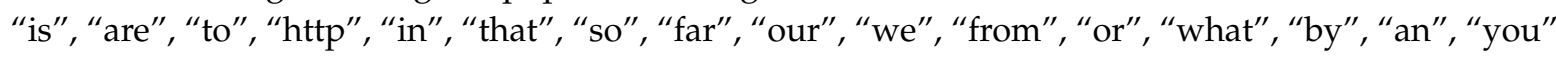
and "after".

Moreover, demographical data was also downloaded from the page, showcasing the distribution of cities and countries of the fans. The data was used to discriminate between fans residing in developed and developing nations to understand the interests of fans in countries with different economic status. To broaden the interests shared by the public on issues related to climate change from developed and 
developing nations, Google Trends data (https://www.google.com/trends) for the widely searched item "climate change" on the Google Search Engine from around the globe were downloaded for the same period. Google Trends data have also been used in the past to discover trends in news related to climate change [2,55]. Note, the Google Trends data are normalized to the time and location of the search to provide a relative measure of interest, where a value of 100 indicates the peak popularity for the search term and a value of 50 depicts that the term was half as popular. Likewise, a score of 0 indicates a lack of data for the search term.

\section{Results}

It is imperative to suggest that the frequency and type of contents shared on the page drive fan engagement. This is illustrated in Figure 1. Except on a few days, daily, around 1-4 posts were added to the page. The average number of total monthly posts added to the page was $\approx 22 \pm 4$. The monthly fluctuation in posts added to the page is illustrated in Figure 1a. A total of 514 posts were added to the page from April 2018 to April 2020.

(a)

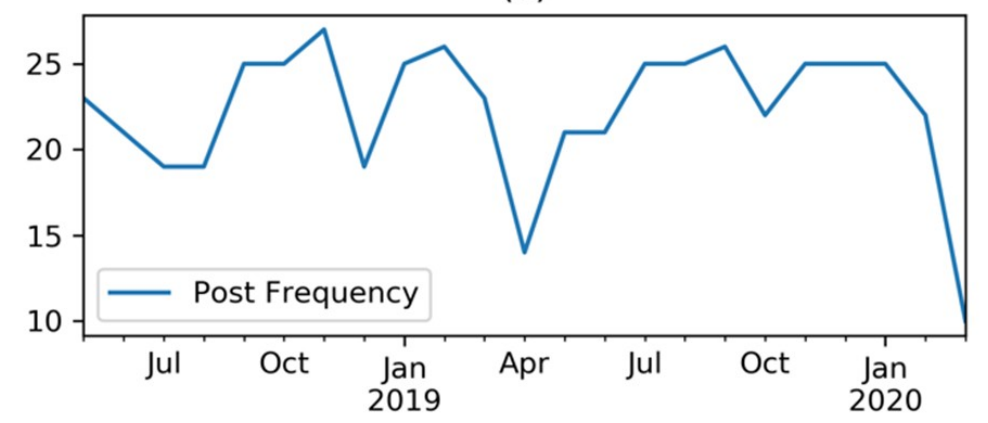

(b)

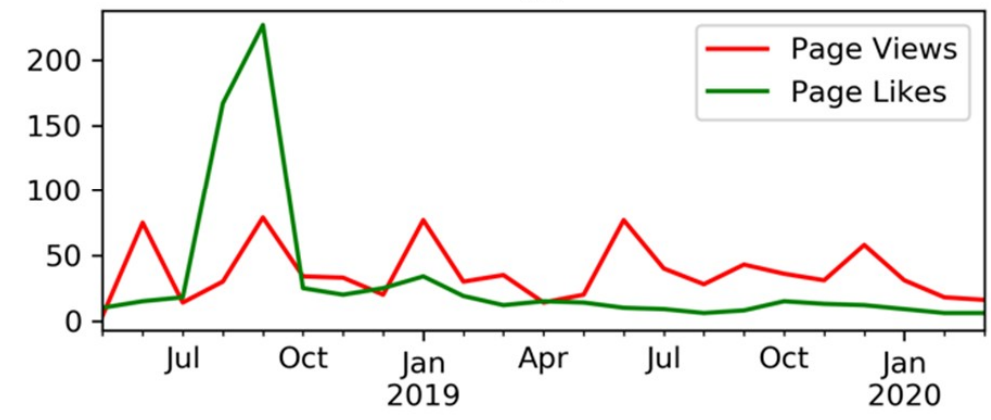

(c)

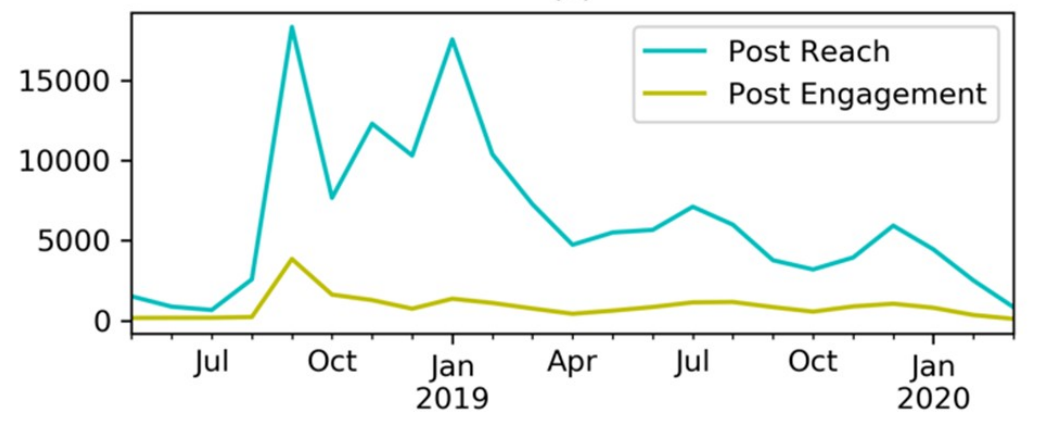

Figure 1. Key monthly page insights; (a) Frequency of the posts made to the page; (b) The number of page views and page likes; (c) The amount of reach and engagement gained by the page posts. 
Generally, the number of people viewing the page is much higher than the likes gained by the page as depicted in Figure 1b. The average number of total monthly likes on the page was $\approx 30 \pm 53$, whereas the average monthly page views were $\approx 37 \pm 22$. A significant variability was observed in page likes, suggesting the number of page likes may be driven by engagement of fans due to the type of contents shared or posted. This is further elaborated in Figure 1c, where the average monthly post engagement $(876 \pm 775)$ is just a fraction of the total monthly averaged post reach $(6220 \pm 4839)$ analogous to the engagement rate $(15 \pm 5 \%)$.

To understand the relationship between the metrics downloaded from the page, a correlation matrix is shown in Figure 2. Further confirmation that the number of posts made to a page does not significantly enhance fan growth is provided by a low correlation $(\approx 0.034)$ of post frequency with page pikes. In fact, post frequency is better correlated with page views and post reach, which is expected with more visibility of contents driving post engagement and page likes. Post engagement was highly correlated with post reach $(\approx 0.81)$. It is highly plausible that post engagement promotes page likes with modest correlations $(\approx 0.61)$ since comments, reactions and shares from current fans may encourage new fan followings.

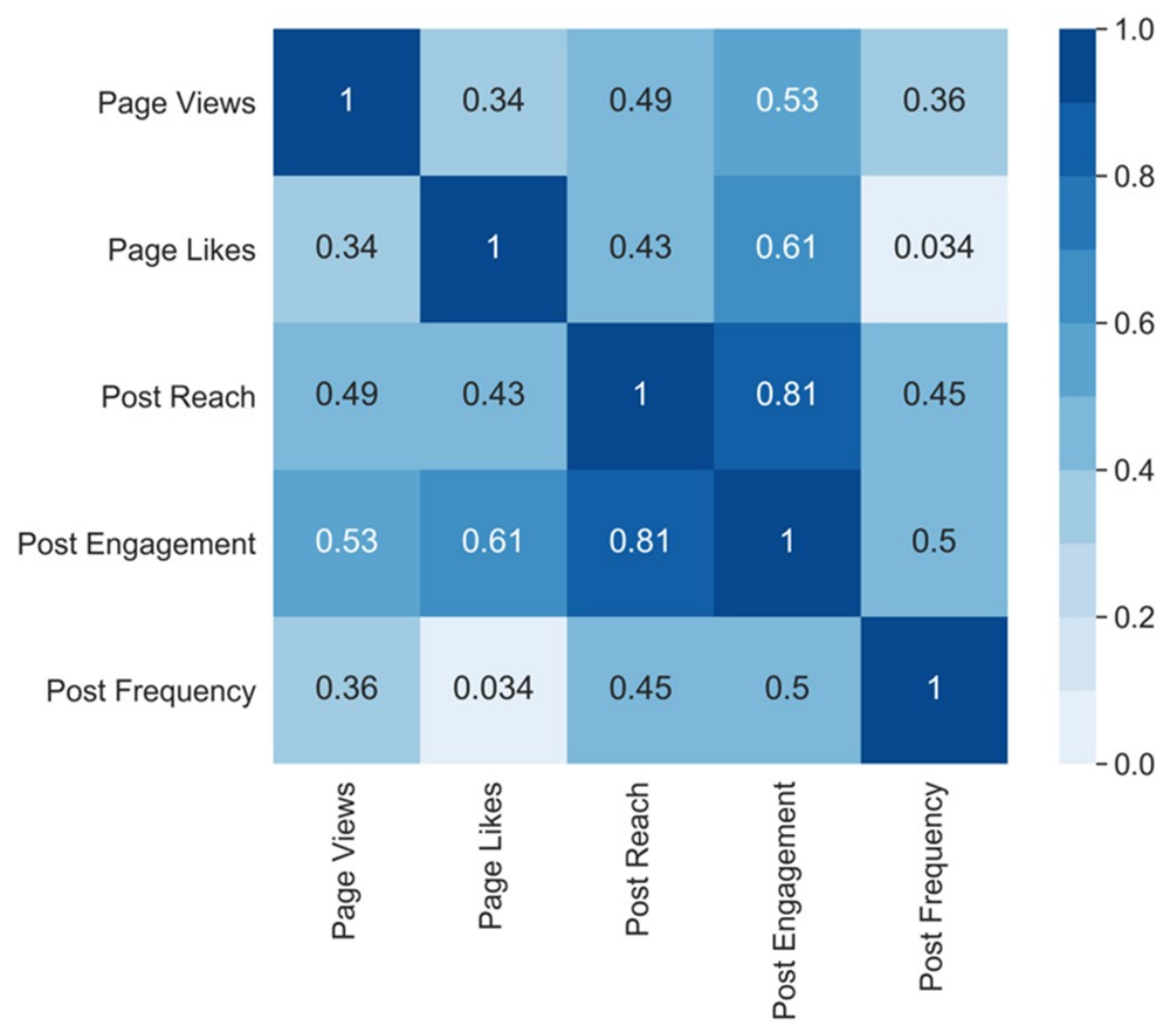

Figure 2. Correlation matrix of monthly page insights.

To further understand the fluctuations in the metrics from the page, the metrics weighted by the post frequency is shown in Figure 3. The weighted metric accounts for the different number of posts generated on the page each month for each metric. All weighted metrics show a decline in trends; however, the trend is highly influenced by the signal near the starting period (late 2018). It is also evident that the strong peaks in all metrics align with each other, indicating that the content of the posts during late 2018 was most engaging. 
(a)

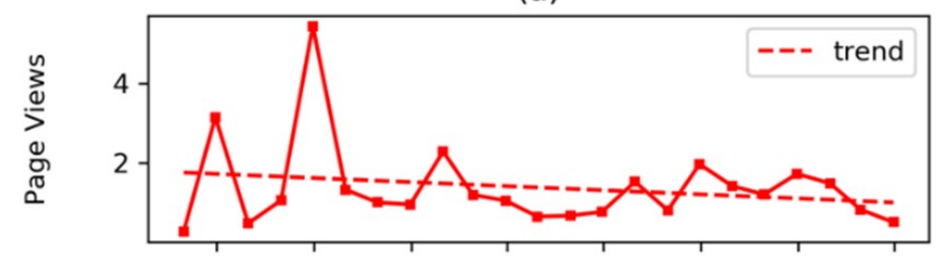

(b)

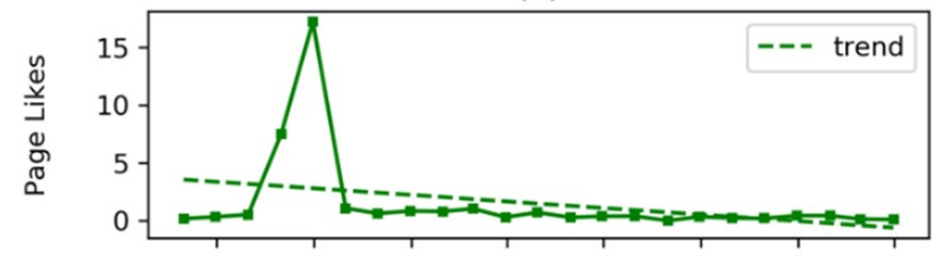

(c)

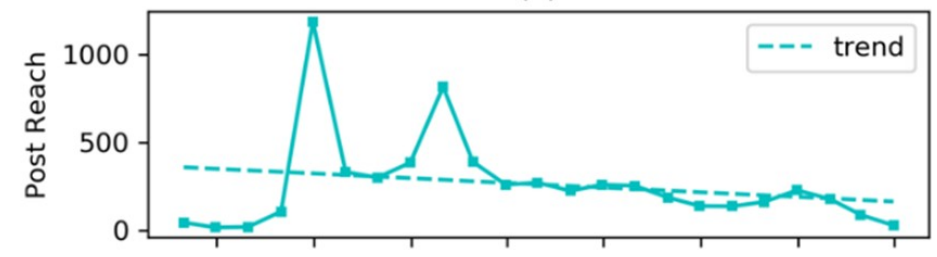

(d)

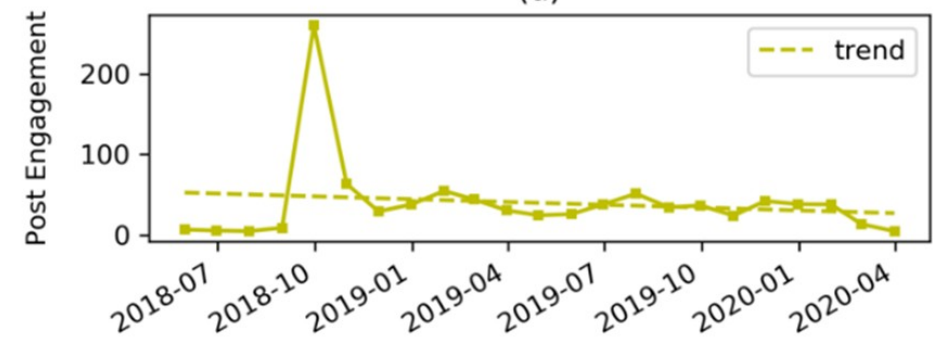

Figure 3. Trends (dashed lines) in weighted metrics (solid lines). (a) Page views; (b) Page likes; (c) Post Reach; (d) Post Engagement.

Figure 4a clearly demonstrates the Lifetime Post Engagement Rate for each post made to the page from its date of creation. On the other hand, the most popular hashtags used in all the posts are shown in Figure $4 \mathrm{~b}$. The contents posted on the page were mostly related to \#climatechange, \#extremeweather, \#globalwarming, \#pollution, \#sealevelrise, \#cyclone, \#bushfire, \#heatwave and \#earthquake.

Most posts made in 2018 were highly engaging (ER: 40-80\%) compared to the rest of the times $(E R<20 \%)$. To further delaminate post performance, all posts with performance metrics above the 95th percentile were further analysed to determine the most popular hashtags. This is illustrated in Figure 5 from Post Engagement Rate, Post Engagement and Post Reach. There are major differences in the contents of posts that are viewed without triggering any user engagement. The posts with highest response rate (ER shown in Figure 5a) include posts associated with disasters (\#hurricane, \#tsunami, \#typhoon, \#flooding), where the page expressing sadness (\#sad) informs people to take precautions (\#please \#take \#care).

Similarly, the posts with only the highest engagement (shown in Figure 5b) included posts not only with disasters (\#tsunami, \#flooding, \#cyclone, \#earthquake) but also included climate change related contents (\#climatechange, \#climate) such as heatwaves (\#warmest, \#warmestperiods) and increasing waste (\#pollution, \#plastic, \#plasticwaste), where the page expressed the magnitude of the problem (\#impact, \#devastating) at times with sadness (\#sad), gratitude (\#thoughts, \#prayers) and precautions (\#pleasetakecare). 
(a)

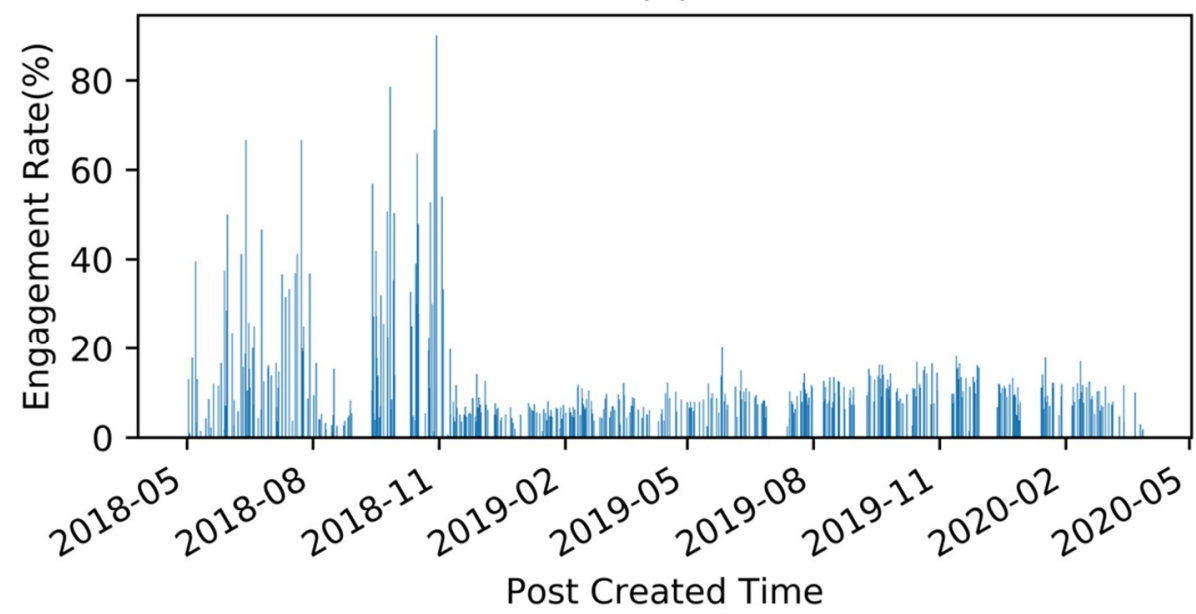

(b)

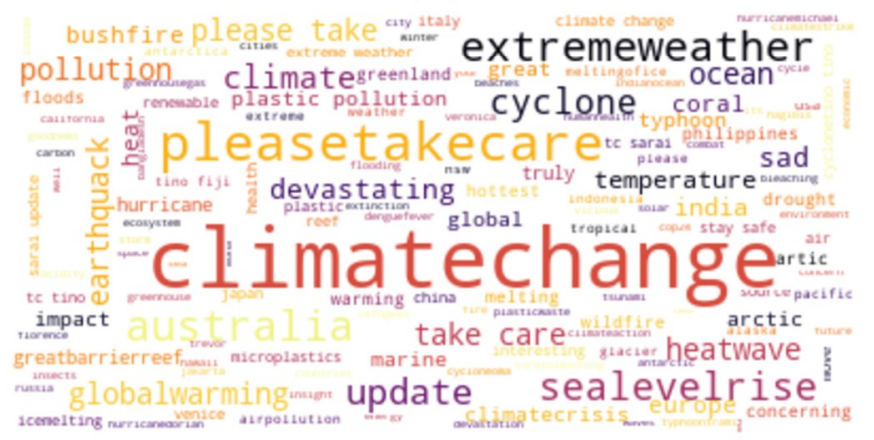

Figure 4. Post insights from the page (a) Lifetime Post Engagement Rate; (b) Word cloud of hashtags for all posts.

(a)

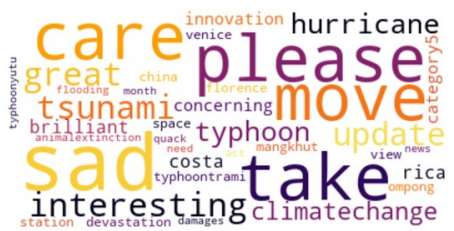

(b)

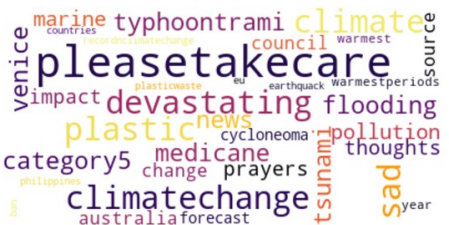

(c)

pollytion greenland $_{\text {between }}$ ieasetakecare betweenpleastsource insight difference cyclone dextremastating

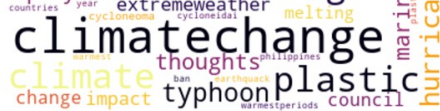

Figure 5. Word cloud of top 95th percentile hashtags from all posts: (a) Lifetime Post Engagement Rate, (b) Lifetime Post Engagement and (c) Lifetime Post Reach.

In contrast, the posts with the highest reach not only included climate change related contents (\#climatechange, \#climate, \#melting, \#oceans) but also included key impacts of climate change (\#extremeweather, \#extreme, \#weather, \#hurricane, \#cyclone, \#typhoon) where the page expressing the magnitude of the problem (\#impact, \#devastating) informs people to take precautions (\#pleasetakecare).

Generally, posts related to both weather and climate impacts reach more people, but people react more to posts expressing major concerns associated with disasters, whether it may be climate or weather related. Posts that have both engagement and reach are driven by the page expressing more concern and gratitude to the people.

Another interesting aspect of fans is the demographics: Figure 6 highlights the major cities and countries where overall Page likes resulted from. Although the fans of the page are distributed globally, most of them are located in Bangladesh and Pacific Island Countries including Fiji, Papua New Guinea 
and Tonga. Comparatively, fans of the page were limited in Europe and USA. The demographics of fans of the page clearly shows that climate change related information is disseminated more in countries directly affected by the impacts of climate change. Bangladesh and Pacific Island Countries are the most vulnerable countries, with rising impacts of extreme weather and climate affecting its people and the economy.

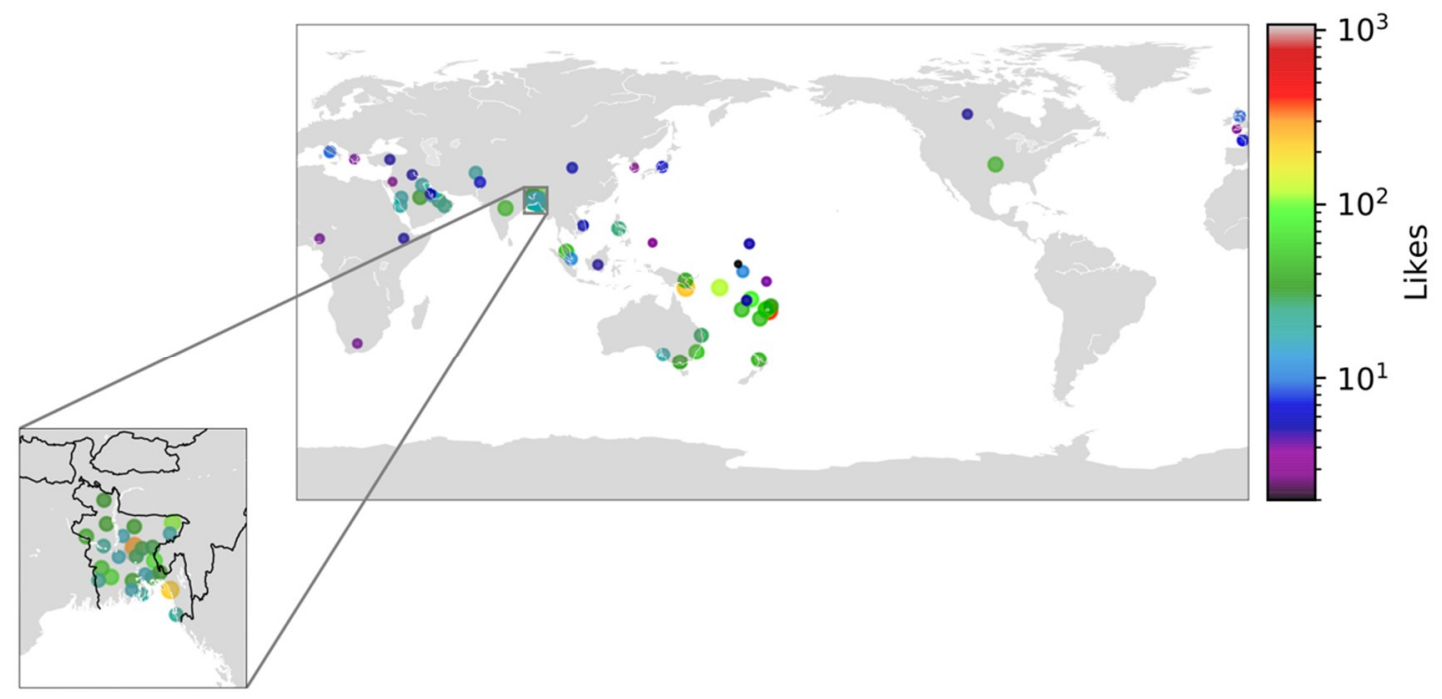

Figure 6. Demographics of fanbase. The insert box shows zoomed region over Bangladesh with the highest combined Page Likes.

Most of these countries also top the widely searched item "climate change" on the Google Search Engine in comparison to more developed countries (UK and USA), with the data available for the same period used in this study downloaded from Google Trends (shown in Figure 7).

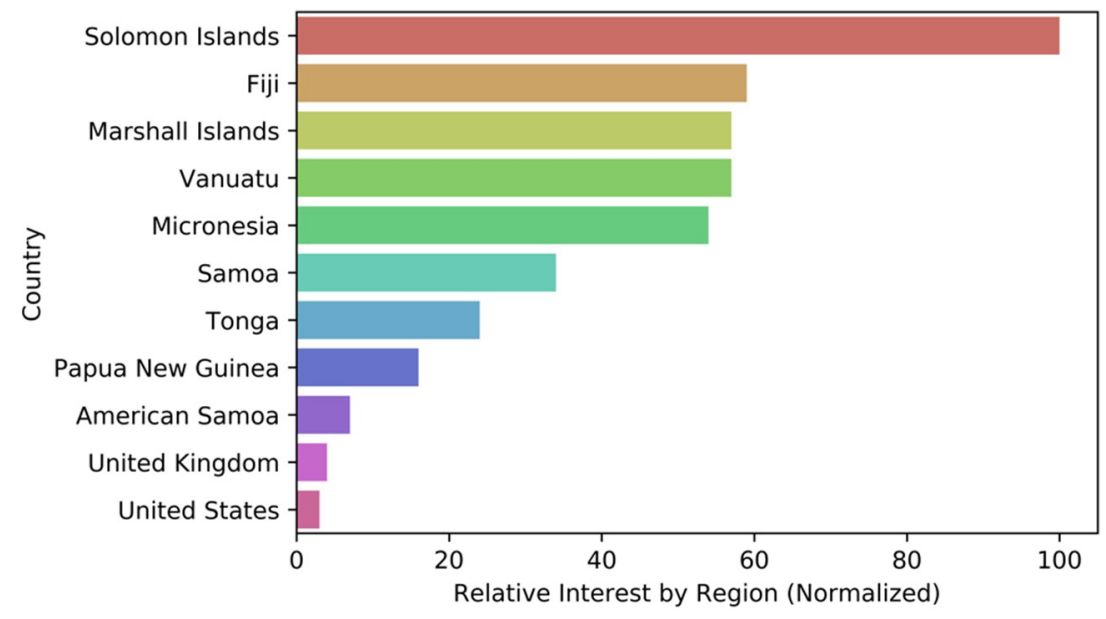

Figure 7. Relative interest by region for the web search term "Climate Change". Data source: Google Trends (https://www.google.com/trends).

Although the user engagement on a Facebook fan-based page and Google engine search intensity cannot be directly compared, the engagement intentions from users seemingly associates to issues related to climate change. Concerns about climate change are greater amongst people from small developing islands than people from developed nations such as UK and USA. 


\section{Discussion}

Climate change awareness through the engagement of fans on Facebook pages depends primarily on the contents shared by the posts. This has been termed as content engagement, especially in the marketing literature where user interaction with the content is critical in sales performance and branding [56]. In this study, credible news and information related to climate change was the most influencing factor in generating likes, shares, comments and reactions to the posts.

Additionally, constantly posting to the page with climate-related news and stories drives post visibility and reach, eventually triggering page likes with new page-based fans. The contents are driving engagement amongst fans related to two broad content categories: climate change (global warming, extreme weather, sea-level rise) and natural disasters (cyclones, bushfires, heatwaves, earthquake).

Climate change-related content had a greater reach since it also encompasses contents related to strong impacts from climate change related to weather and climate disasters. This covers a broader content with possibilities to reach more people. However, weather and climate disaster-related content initiate greater engagement. While there is a strong link to the increasing number of natural disasters due to climate change [57], it is clear that people would respond strongly to the increasing number of disasters that directly impact livelihoods of people. Cody, et al. [27] also showed that natural disasters were more commonly discussed amongst climate-related tweets. Several other studies have also reported similar results, which are reviewed in Fownes, et al. [24].

The emotions and gratitude expressed on posts of the page curators gathered better responses from fans. There is strong evidence that emotions expressed can influence engagement on social media platforms. Lin and Utz [41] identified that the emotional connection of users on Facebook were significantly affected by the content of the posts, the readers' personal traits and the relationship between the readers and the poster. In this study, the content of the posts significantly determined the Lifetime Post Engagement Reach, especially when the poster expresses strong emotions on the post. It suffices to say that the emotions expressed by the poster and those perceived by the reader are common to both, thus generating an emotional bond. It is highly likely that both the reader and the poster express similar personal traits, especially in terms of the attitude towards supporting climate change-related news. Our results also support the conceptual framework developed by [58], where the content characteristics influence content engagement through psychological processes such as attitudes and emotions.

This study highlights that the people residing in countries such as Bangladesh and Pacific Island nations face the direct brunt of extreme weather and climate-related disasters are at the forefront of climate change-related news and awareness [59,60], thus such communities of people may further create awareness in other countries through their experiences and emotions on social media.

\section{Conclusions}

The generation of climate change awareness on social media by engaging the general public with rich and valid information may develop new policies in the transition to a more sustainable future. The relationship between the content posted on social media and the content curating engagement is likely mediated by behavioural responses of both the user and the poster. Although such connections in the engagement behaviour of users on Twitter in communicating climate change information has been extensively explored in the past, fan-based pages on Facebook with intensions to raise climate change awareness have been not extensively explored.

This paper assessed the engagement behaviour of users on a Facebook fan-based page titled "Global Climate Change Awareness" by analysing user insights data for the page and the posts retrieved using the Graph API, version 6.0 (Facebook, Silicon Valley, CA, USA) and the Python Facebook SDK for a two-year period starting from April 2018 to April 2020. The key metrics available from the user insights data show that users engage on the Facebook fan-based page through Page Views, Page Likes, Post Reach and Post Engagement. The metrics including Page Views and Post Reach show only the visibility of the content to the users, but the Page Likes and Post Engagement denote a response from 
the users through likes, reactions, comments and shares. On the other hand, the frequency of the posts highlighted the rate at which contents were made available on the page.

Results show that the frequency of posts made to the page did not promote fan growth (correlations $<0.04$ ) but increased the page visibility (Page Views), likely through more engaging contents (Post Engagement). Furthermore, Post Engagement was highly correlated with Post Reach $(\approx 0.81)$, showing post visibility triggered more engagement. Higher engagement from posts made to the page likely promoted Page Likes since comments, reactions and shares from current fans may have attracted new fans.

Moreover, fluctuations in the visibility (Page Views and Post Reach) and engagement (Page Likes and Post Engagement) weighted by the frequency of posts made to the page all showed a declining trend sensitive to data at the starting period of the signal (late 2018). During late 2018, the lifetime engagement rate of posts was much higher $(40-80 \%)$ compared to the rest of the period $(<20 \%)$, indicating the relevance of the contents of the posts in driving user engagement behaviour. The most popular hashtags creating awareness on the page included \#climatechange, \#extremeweather, \#globalwarming, \#pollution, \#sealevelrise, \#cyclone, \#bushfire, \#heatwave and \#earthquake.

Further investigation of the top 95th percentile of posts with the greatest engagement rate, Post Reach and Post Engagement showed interesting connections with emotions shared on the posts. Hashtags associated with disasters (\#hurricane, \#tsunami, \#typhoon, \#flooding) where the page expressed sadness (\#sad) and informed people to take precautions (\#please \#take \#care) had the greatest engagement rate. On the other hand, posts with greater visibility were related to the broader climate change related issues, while posts with greater engagement were related more to natural disasters. Hence, psychological attributes of the user consuming the contents related to climate change on social media moderates the intensity of content engagement, which is likely to strongly influence climate change awareness communication on social media. Another interesting outcome of this study showed the discrepancies in climate change awareness on social media amongst the developed and the developing countries (especially the small islands), where the latter show increased awareness on climate change issues due to evidence of direct threats posed in the current climate due to increasing weather and climate extremes.

The study was limited to a two-year period with analysis conducted for only a single fan-based page restricting the generalization of results presented to a broader population. However, this limitation was primarily due to data policy and privacy measures introduced by Facebook regulating access to data from similar fan-based pages. The possibility of exploring more fan-based pages covering social media awareness would be desirable, nonetheless this study showcases the potential of individual fan-based pages in creating awareness through engagement on issues relating to climate change to people from around the globe. The study can also be extended to explore the information shared with the popular hashtags through text mining and sentiment analysis. Also, this study did not analyse negative responses from users likely to be climate deniers, which bring in another dimension and adds more complexity to the current assessment with a possibility for extended future research.

Author Contributions: Conceptualization, K.D.; methodology, K.D.; software, A.A.P.; validation, K.D. and A.A.P.; formal analysis, K.D.; investigation, K.D.; resources, A.A.P.; data curation, A.A.P.; writing-original draft preparation, K.D.; writing-review and editing, K.D. and A.A.P.; visualization, A.A.P.; supervision, A.A.P.; project administration, K.D.; funding acquisition, A.A.P. All authors have read and agreed to the published version of the manuscript.

Funding: This research received no external funding.

Acknowledgments: We would like to thank Facebook for hosting and providing access to the data for the page titled "Global Climate Change Awareness". We also acknowledge the team and management of the page for posting regular and relevant contents to the page. We appreciate the helpful suggestions of the anonymous reviewers that greatly improved the manuscript.

Conflicts of Interest: The authors declare no conflict of interest. 


\section{References}

1. Carvalho, A. Climate change as a 'grand narrative'. J. Sci. Commun. 2010, 9, 1-4. [CrossRef]

2. Mavrodieva, A.V.; Rachman, O.K.; Harahap, V.B.; Shaw, R. Shaw role of social media as a soft power tool in raising public awareness and engagement in addressing climate change. Climate 2019, 7, 122. [CrossRef]

3. Roxburgh, N.; Guan, D.; Shin, K.J.; Rand, W.; Managi, S.; Lovelace, R.; Zheng, H. Characterising climate change discourse on social media during extreme weather events. Glob. Environ. Chang. 2019, 54, 50-60. [CrossRef]

4. Evans, D.; McKee, J.; Bratton, S. Praise for Social Media Marketing: The Next Generation for Business Engagement; Wiley Publishing: Hoboken, NJ, USA, 2010; p. 410.

5. Kietzmann, J.; Hermkens, K.; McCarthy, I.P.; Silvestre, B.S. Social media? Get serious! Understanding the functional building blocks of social media. Bus. Horizons 2011, 54, 241-251. [CrossRef]

6. Anderson, A.A. Effects of social media use on climate change opinion, knowledge, and behavior. Oxf. Res. Encycl. Clim. Sci. 2017, 1-20. [CrossRef]

7. Kaplan, A.M.; Haenlein, M. Users of the world, unite! The challenges and opportunities of social media. Bus. Horizons 2010, 53, 59-68. [CrossRef]

8. Chen, X.; Zou, L.; Zhao, B. Detecting climate change deniers on twitter using a deep neural network. In Proceedings of the 2019 11th International Conference on Machine Learning and Computing-ICMLC '19. Association for Computing Machinery (ACM), Zhuhai, China, 22-24 February 2019; pp. 204-210.

9. Lineman, M.; Do, Y.; Kim, J.Y.; Joo, G.-J. Talking about climate change and global warming. PLoS ONE 2015, 10, e0138996. [CrossRef]

10. Titifanue, J.; Kant, R.; Finau, G.; Tarai, J. Climate change advocacy in the Pacific: The role of information and communication technologies. Pac. J. Rev. Te Koakoa 2017, 23, 133-149. [CrossRef]

11. Kryvasheyeu, Y.; Chen, H.; Obradovich, N.; Moro, E.; Van Hentenryck, P.; Fowler, J.H.; Cebrian, M. Rapid assessment of disaster damage using social media activity. Sci. Adv. 2016, 2, e1500779. [CrossRef]

12. Napawan, N.C.; Simpson, S.-A.; Snyder, B. Engaging youth in climate resilience planning with social media: Lessons from \#ourchangingclimate. Urban Plan. 2017, 2, 51. [CrossRef]

13. Niles, M.T.; Emery, B.F.; Reagan, A.J.; Dodds, P.S.; Danforth, C.M. Social media usage patterns during natural hazards. PLoS ONE 2019, 14, e0210484. [CrossRef]

14. Beg, N.; Morlot, J.C.; Davidson, O.; Afrane-Okesse, Y.; Tyani, L.; Denton, F.; Sokona, Y.; Thomas, J.P.; La Rovere, E.; Parikh, J.K.; et al. Linkages between climate change and sustainable development. Clim. Policy 2002, 2, 129-144. [CrossRef]

15. Byrne, J.; Wanga, Y.-D.; Lee, H.; Kim, J.-D. An equity-And sustainability-based policy response to global climate change. Energy Policy 1998, 26, 335-343. [CrossRef]

16. Weaver, D. Can sustainable tourism survive climate change? J. Sustain. Tour. 2011, 19, 5-15. [CrossRef]

17. Nisbet, M.C. Communicating climate change: Why frames matter for public engagement. Environ. Sci. Policy Sustain. Dev. 2009, 51, 12-23. [CrossRef]

18. Marquart-Pyatt, S.T.; Shwom, R.L.; Dietz, T.; Dunlap, R.E.; Kaplowitz, S.A.; McCright, A.M.; Zahran, S. Understanding public opinion on climate change: A call for research. Environment 2011, 53, 38-42. [CrossRef]

19. Anderson, A.A.; Huntington, H. Social media, science, and attack discourse: How twitter discussions of climate change use sarcasm and incivility. Sci. Commun. 2017, 39, 598-620. [CrossRef]

20. Jiang, H.; Qiang, M.; Zhang, D.; Wen, Q.; Xia, B.; An, N. Climate change communication in an online q\&a community: A case study of quora. Sustainability 2018, 10, 1509. [CrossRef]

21. Andreotta, M.; Nugroho, R.; Hurlstone, M.J.; Boschetti, F.; Farrell, S.; Walker, I.; Paris, C. Analyzing social media data: A mixed-methods framework combining computational and qualitative text analysis. Behav. Res. Methods 2019, 51, 1766-1781. [CrossRef]

22. Dahal, B.; Kumar, S.A.P.; Li, Z. Topic modeling and sentiment analysis of global climate change tweets. Soc. Netw. Anal. Min. 2019, 9, 24. [CrossRef]

23. Hamed, A.A.; Ayer, A.A.; Clark, E.M.; Irons, E.A.; Taylor, G.T.; Zia, A. Measuring climate change on Twitter using Google's algorithm: Perception and events. Int. J. Web Inf. Syst. 2015, 11, 527-544. [CrossRef]

24. Fownes, J.R.; Yu, C.; Margolin, D. Twitter and climate change. Sociol. Compass 2018, 12, e12587. [CrossRef] 
25. Singleton, S.; Kumar, S.A.; Li, Z. Twitter analytics-based assessment: Are the United States coastal regions Prepared for Climate Change. In Proceedings of the 2018 IEEE International Symposium on Technology and Society (ISTAS), Washington, DC, USA, 13-14 November 2018; pp. 150-155.

26. Samantray, A.; Pin, P. Credibility of climate change denial in social media. Palgrave Commun. 2019, 5, 1-8. [CrossRef]

27. Cody, E.M.; Reagan, A.J.; Mitchell, L.; Dodds, P.S.; Danforth, C.M. Climate change sentiment on twitter: An unsolicited public opinion poll. PLoS ONE 2015, 10, e0136092. [CrossRef] [PubMed]

28. Vraga, E.K.; Anderson, A.A.; Kotcher, J.; Maibach, E.W. Issue-Specific Engagement: How Facebook contributes to opinion leadership and efficacy on energy and climate ISSUES. J. Inf. Technol. Polit. 2015, 12, 200-218. [CrossRef]

29. Katz-Kimchi, M.; Manosevitch, I. Mobilizing Facebook users against Facebook's energy policy: The Case of greenpeace unfriend coal campaign. Environ. Commun. 2015, 9, 248-267. [CrossRef]

30. Bird, D.; Ling, M.; Haynes, K. Flooding Facebook-The use of social media during the Queensland and Victorian floods. Aust. J. Emerg. Manag. 2012, 27, 27-33.

31. Pearce, W.; Niederer, S.; Özkula, S.M.; Querubín, N.S. The social media life of climate change: Platforms, publics, and future imaginaries. Wiley Interdiscip. Rev. Clim. Chang. 2018, 10, e569. [CrossRef]

32. Brailovskaia, J.; Bierhoff, H.-W.; Rohmann, E.; Raeder, F.; Margraf, J. The relationship between narcissism, intensity of Facebook use, Facebook flow and Facebook addiction. Addict. Behav. Rep. 2020, 11, 100265. [CrossRef]

33. Hsu, L.-C.; Wang, K.-Y.; Chih, W.-H.; Lin, K.-Y. Investigating the ripple effect in virtual communities: An example of Facebook fan pages. Comput. Hum. Behav. 2015, 51, 483-494. [CrossRef]

34. Sabaté, F.; Berbegal-Mirabent, J.; Canabate, A.; Lebherz, P.R. Factors influencing popularity of branded content in Facebook fan pages. Eur. Manag. J. 2014, 32, 1001-1011. [CrossRef]

35. Rosenthal, B.; Brito, E.P.Z. How virtual brand community traces may increase fan engagement in brand pages. Bus. Horizons 2017, 60, 375-384. [CrossRef]

36. De Vries, L.; Gensler, S.; Leeflang, P.S. Popularity of brand posts on brand fan pages: An investigation of the effects of social media marketing. J. Interact. Mark. 2012, 26, 83-91. [CrossRef]

37. Park, N.; Kee, K.F.; Valenzuela, S. Being immersed in social networking environment: Facebook groups, uses and gratifications, and social outcomes. CyberPsychology Behav. 2009, 12, 729-733. [CrossRef]

38. Kang, J.; Tang, L.; Fiore, A.M. Enhancing consumer-brand relationships on restaurant Facebook fan pages: Maximizing consumer benefits and increasing active participation. Int. J. Hosp. Manag. 2014, 36, 145-155. [CrossRef]

39. Lin, K.-Y.; Lu, H.-P. Intention to continue using Facebook fan pages from the perspective of social capital theory. Cyberpsychology Behav. Soc. Netw. 2011, 14, 565-570. [CrossRef] [PubMed]

40. Connor, P.; Harris, E.; Guy, S.; Fernando, J.; Shank, D.B.; Kurz, T.; Bain, P.G.; Kashima, Y. Interpersonal communication about climate change: How messages change when communicated through simulated online social networks. Clim. Chang. 2016, 136, 463-476. [CrossRef]

41. Lin, R.; Utz, S. The emotional responses of browsing Facebook: Happiness, envy, and the role of tie strength. Comput. Hum. Behav. 2015, 52, 29-38. [CrossRef]

42. Roeser, S. Risk communication, public engagement, and climate change: A role for emotions. Risk Anal. 2012, 32, 1033-1040. [CrossRef]

43. Huertas, A.; Marine-Roig, E. User reactions to destination brand contents in social media. Inf. Technol. Tour. 2015, 15, 291-315. [CrossRef]

44. Gummerus, J.; Liljander, V.; Weman, E.; Pihlström, M. Customer engagement in a Facebook brand community. Manag. Res. Rev. 2012, 35, 857-877. [CrossRef]

45. Chen, M.-H.; Tsai, K.-M. An empirical study of brand fan page engagement behaviors. Sustainability 2020, 12, 434. [CrossRef]

46. Dolan, R.; Conduit, J.; Fahy, J.; Goodman, S. Social media engagement behaviour: A uses and gratifications perspective. J. Strat. Mark. 2015, 24, 261-277. [CrossRef]

47. Doorn, V.J.; Lemon, N.K.; Mittal, V.; Nass, S.; Pick, D.; Pirner, P.; Verhoef, C.P. Customer engagement behavior: Theoretical foundations and research directions. J. Serv. Res. 2010, 13, 253-266. [CrossRef]

48. Schivinski, B.; Dabrowski, D. The effect of social media communication on consumer perceptionsof brands. J. Mark. Commun. 2016, 22, 189-214. [CrossRef] 
49. Williams, H.T.P.; McMurray, J.R.; Kurz, T.; Lambert, F.H. Network analysis reveals open forums and echo chambers in social media discussions of climate change. Glob. Environ. Chang. 2015, 32, 126-138. [CrossRef]

50. Weaver, J.; Tarjan, P. Facebook linked data via the graph api. Semantic Web 2013, 4, 245-250. [CrossRef]

51. Nguyen, T.T.; Kravets, A.G. Analysis of the social network facebook comments. In Proceedings of the 2016 7th International Conference on Information, Intelligence, Systems \& Applications (IISA), Chalkidiki, Greece, 13-15 July 2016; pp. 1-5. [CrossRef]

52. Nadzir, M.M.; Harun, N.H.; Hassan, M.G. Social media engagement on Malaysian government agencies Facebook pages: An empirical analysis. In Proceedings of the 2019 IEEE Jordan International Joint Conference on Electrical Engineering and Information Technology (JEEIT), Amman, Jordan, 9-11 April 2019; Institute of Electrical and Electronics Engineers (IEEE): Piscataway, NJ, USA, 2019; pp. 717-719.

53. Fähnrich, B.; Vogelgesang, J.; Scharkow, M. Evaluating universities' strategic online communication: How do Shanghai Ranking's top 50 universities grow stakeholder engagement with Facebook posts? J. Commun. Manag. 2020, 10, 1108. [CrossRef]

54. Van Der Walt, S.J.; Colbert, S.C.; Varoquaux, G. The numpy array: A structure for efficient numerical computation. Comput. Sci. Eng. 2011, 13, 22-30. [CrossRef]

55. Lewandowsky, S. Conspiratory fascination versus public interest: The case of 'climategate'. Environ. Res. Lett. 2014, 9, 111004. [CrossRef]

56. Hudson, S.; Huang, L.; Roth, M.S.; Madden, T.J. The influence of social media interactions on consumer-brand relationships: A three-country study of brand perceptions and marketing behaviors. Int. J. Res. Mark. 2016, 33, 27-41. [CrossRef]

57. Easterling, D.R. Climate extremes: Observations, modeling, and impacts. Science 2000, 289, $2068-2074$. [CrossRef] [PubMed]

58. Schreiner, M.; Fischer, T.; Riedl, R. Impact of content characteristics and emotion on behavioral engagement in social media: Literature review and research agenda. Electron. Commer. Res. 2019, 1-17. [CrossRef]

59. Nurunnabi, M. Who cares about climate change reporting in developing countries? The market response to, and corporate accountability for, climate change in Bangladesh. Environ. Dev. Sustain. 2015, 18, 157-186. [CrossRef]

60. Hay, J.E.; Forbes, D.L.; Mimura, N. Understanding and managing global change in small islands. Sustain. Sci. 2013, 8, 303-308. [CrossRef] 